\title{
Matérista
}

Revista Matéria, v. 14, n. 4, pp. 1172 - 1178, 2009

SSN 1517-7076

http://www.materia.coppe.ufrj.br/sarra/artigos/artigo11016

\section{Avaliação das propriedades físicas e mecânicas de papéis reciclados artesanais com resíduos de bananeira ou palha de arroz}

\author{
BASTIANELLO ${ }^{\mathrm{I}}$, S.F.; TESTA ${ }^{\mathrm{II}}$, R.C.; PEZZIN ${ }^{\mathrm{III}}$, A.P.T.; SILVA ${ }^{\mathrm{I}}$, D.A.K. \\ ${ }^{\text {I }}$ Programa de Mestrado em Saúde e Meio Ambiente - UNIVILLE CP 246 - 89201-972, Joinville, Santa \\ Catarina, SC. \\ e-mail: vivacedipv@yahoo.com.br, dabatti@univille.edu.br

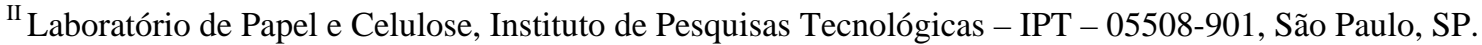 \\ e-mail: rctesta@ipt.br \\ ${ }^{\text {III }}$ Programa de Mestrado em Engenharia de Processos - UNIVILLE CP 246 - 89201-972 Joinville, Santa \\ Catarina, SC. \\ e-mail: anapezzin@yahoo.com.br
}

\section{RESUMO}

As culturas de banana e arroz são predominantes na região Nordeste do Estado de Santa Catarina e no caso da banana chegam a gerar 200 toneladas/ano de resíduos entre, pseudocaules, engaços e folhas, que geralmente são incorporados ao solo. Desta forma, este trabalho teve como objetivo avaliar a influência da adição de polpa de fibras vegetais nas propriedades físicas e mecânicas de papéis reciclados de forma artesanal, bem como reaproveitar os resíduos gerados por estas culturas. As polpas contendo fibras de palha de arroz ou de pseudocaule de bananeira foram acrescentadas à polpa de papel nas proporções de 0, 10, 20 e 30 \% em massa $(\mathrm{m} / \mathrm{m})$ e as folhas obtidas foram submetidas aos ensaios de gramatura, espessura, permeância ao ar, resistência à tração, resistência ao esmagamento do anel e resistência ao arrebentamento segundo normas NBR apropriadas. Analisados os ensaios físicos e mecânicos, constatou-se que os resultados mais expressivos foram registrados para as folhas que continham $20 \%(\mathrm{~m} / \mathrm{m})$ de pasta de bananeira.

Palavras-chaves: propriedades físicas e mecânicas, fibras de bananeira, fibras de arroz, papel reciclado artesanal, resíduos agroindustriais.

\section{Evaluation of physical and mechanical properties of handmade recycled papers reinforced with pulp of banana tree or rice straw}

\section{ABSTRACT}

The cultures of bananas and rice are predominant in the Northeast of Santa Catarina State and in the case of banana the, reach 200 ton/year of waste, including pseudo-stem, stalks and leaves, which are usually incorporated into the soil. Thus, this work analyzed the physical-mechanics properties of handmade papers produced with recycled fibers with local agro-industry resources, pulps of banana tree (Musa cavendishii) and rice straw (Oriza sativa). Handmade papers were produced with the mixtures whose compositions had 10 $\%, 20 \%$ and $30 \mathrm{wt} \%$ of banana or rice pulps. The compounds produced were using physical and mechanical tests, such as: gramature, thickness, porosity, tensile strength, crushing of the ring strength, and stretching strength in agreement with appropriated NBRs. The physical and mechanical tests pointed out that the samples with $20 \%$ of banana pulp present more expressive results.

Keywords: physical-mechanics properties, banana fibers, rice straw fibers, handmade recycled paper, agrobased resources

\section{INTRODUÇÃO}

A necessidade de utilizar matérias primas alternativas e de baixo custo, além da problemática de descarte e acúmulo de resíduos, têm intensificado o uso de materiais recicláveis [1]. Atualmente, a discussão sobre a relação custo/benefício ambiental do processo de reciclagem de papel envolve opiniões distintas. Por um lado, uma plantação de 200.000 hectares de pinus ou eucaliptos absorve cerca de 5 milhões de toneladas 
de carbono por ano [2], o que acarreta na fixação de dióxido de carbono apontado como principal causador do efeito estufa. Por outro lado, a reciclagem representa um processo socioeconômico importante, pois permite a geração de emprego e renda, além de ser um tema que requer da sociedade uma postura proativa no que diz respeito à separação, coleta e destinação final. Os consumidores dos produtos reciclados valorizam e procuram pela qualidade ambiental. Estes são alguns dos motivos pelos quais a reciclagem de papéis vem ao longo dos anos atingindo importância internacional. Neste contexto, o projeto Mulher com Fibra foi um trabalho de extensão universitária desenvolvido pela Universidade da Região de Joinville (UNIVILLE) com o apoio da Fundação Municipal de Desenvolvimento Rural, 25 de Julho e da OSCIP Instituto Consulado da Mulher e que teve como objetivo desenvolver produtos em produção comunitária a partir de resíduos de papel de escritório e de subprodutos do cultivo da banana como alternativa de geração de renda para mulheres artesãs da região de Joinville [3, 4].

Os estudos que discorrem sobre a reciclagem de resíduos, as análises de ciclo de vida e os possíveis impactos desses processos sobre o aquecimento global nem sempre apontam a reciclagem como melhor alternativa perante a incineração ou aterramento. Entretanto, Villanueva [5], após revisar 9 estudos de ciclo de vida contendo 73 cenários, identificou que a reciclagem de papel parece ter leve vantagem sobre processos de incineração e aterramento.

Dentre as possibilidades, surge a aplicação de resíduos agroindustriais locais, uma tendência na obtenção de materiais compósitos [ㅌ, $\underline{7}]$. Na agricultura moderna brasileira há destaque para os resíduos do beneficiamento de soja, café, milho, cana-de-açúcar, banana, arroz.

O Brasil é o quarto maior produtor de banana do mundo (cerca de $7.098 .350 \mathrm{t}$ em 2007), ficando atrás da Î́ndia, China e Filipinas [8]. Segundo Soffner [9], a cultura da banana está distribuída por todo o território brasileiro, destacando-se os Estados do Pará, São Paulo, Bahia, Amazonas, Minas Gerais e Santa Catarina. As espécies mais cultivadas são a Musa sapientum, cultivar prata; e Musa cavendishii, cultivares nanica e nanicão. Santa Catarina foi considerado em 2007/08 o terceiro estado em produção (683.156 t correspondendo a $10 \%$ do total) [8], sendo prática comum entre os agricultores familiares. Os resíduos gerados durante a colheita da fruta estão na ordem de 200 toneladas/ano entre, pseudocaules, engaços e folhas, que geralmente são incorporados ao solo. Esta cultura apresenta elevada importância social e econômica em algumas regiões do país por ser uma fonte de alimento, geradora de renda e ainda permitir a manutenção da mão de obra no campo.

No caso do arroz, Santa Catarina foi considerado em 2006 o segundo maior produtor do Brasil, conforme dados da Companhia Brasileira de Abastecimento, Conab. De acordo com a AGENDA 21 a cultura de arroz é representativa no Estado por sua área plantada [10]. Apesar de ser uma cultura anual, com ciclo de apenas 100 a 150 dias [11], portanto produtora de reduzida massa verde, sua área plantada justifica uma abordagem do uso de seus resíduos, principalmente, por apresentar até duas colheitas, sendo que nos demais meses do ano o agricultor fica ocioso e sem renda [10]. Além disso, os resíduos gerados durante o período de colheita dessas culturas não apresentam aplicação nobre e, na maioria dos casos permanece no solo ou servem de alimento para os animais [12].

Observa-se que as alternativas de utilização desses resíduos na fabricação de papel indicadas na literatura propõem desde a aplicação de fibras não-madeireiras consorciadas à polpa de madeira [13] até estudos de viabilidade de substituição de polpas à base de eucalipto e pinus [14]. Um estudo recente do grupo apresenta o desenvolvimento de uma embalagem presenteável a base de papel reciclado com fibras vegetais [15-16].

A proposta deste trabalho foi, a partir de rebarbas de papel branco reciclado de forma artesanal, adicionar pastas vegetais não-madeireiras provenientes de resíduos agrícolas abundantes na Região Nordeste de Santa Catarina, banana ou palha de arroz, em concordância com as questões de reaproveitamento e valorização de resíduos gerados localmente na perspectiva de propor uma alternativa de renda para grupos do interior do município. Assim, amostras de papéis reciclados foram obtidas adicionando-se 0, 10, 20 e $30 \%$ $(\mathrm{m} / \mathrm{m})$ de pasta de bananeira ou de palha de arroz e avaliadas quanto ao desempenho físico e mecânico.

\section{METODOLOGIA}

\subsection{Confecção das folhas}

O papel artesanal possui métodos conhecidos de produção que pode ser adaptado de acordo com a infraestrutura disponível. A metodologia utilizada neste trabalho para a obtenção das folhas de papel artesanal baseou-se naquela descrita por Josep Assunción [17] e segue o fluxograma ilustrado na Figura 1. As aparas de papel de escritório foram picotadas, desinfectadas com hipoclorito de sódio $(50 \mathrm{~mL} / \mathrm{kg})$, lavadas três vezes, cozidas em solução de hidróxido de sódio $(\mathrm{NaOH})(0,05 \mathrm{~g} / \mathrm{L})$ por 30 minutos e lavadas novamente por três vezes. Em seguida, o material cozido foi polpado e refinado em liquidificador tradicional mantendose a proporção polpa/água de $100 \mathrm{~g} / \mathrm{L}$. Na etapa de refino acrescentou-se o agente aglutinante $(10 \% \mathrm{~m} / \mathrm{v})$, 
neste caso cola branca à base de poli(álcool vinílico) (PVA). As pastas de pseudocaule de bananeira e da casca de arroz também passaram pelos processos de picotagem, desinfecção, cozimento em NaOH, lavagem e polpação, como descrito anteriormente. As pastas vegetais foram acrescentadas à polpa de papel nas proporções de 0 (controle), 10, 20 e $30 \%(\mathrm{~m} / \mathrm{m})$, posteriormente prensadas duas vezes (a primeira sob 10 t e a segunda sob 6 t) em prensa hidráulica, manual, com capacidade de 15 t. Em seguida, as folhas mistas de papel e fibra vegetal resultantes foram dispostas sobre tecido não tecido (TNT), secas em varal comum por 24 h, destacadas do suporte flexível e armazenadas soprepostas em local seco e arejado. Foram confeccionadas 6 folhas tamanho A4 e 3 folhas tamanho A3 (42 X 29,7cm) para todas as proporções de pasta de bananeira ou arroz/polpa de papel.

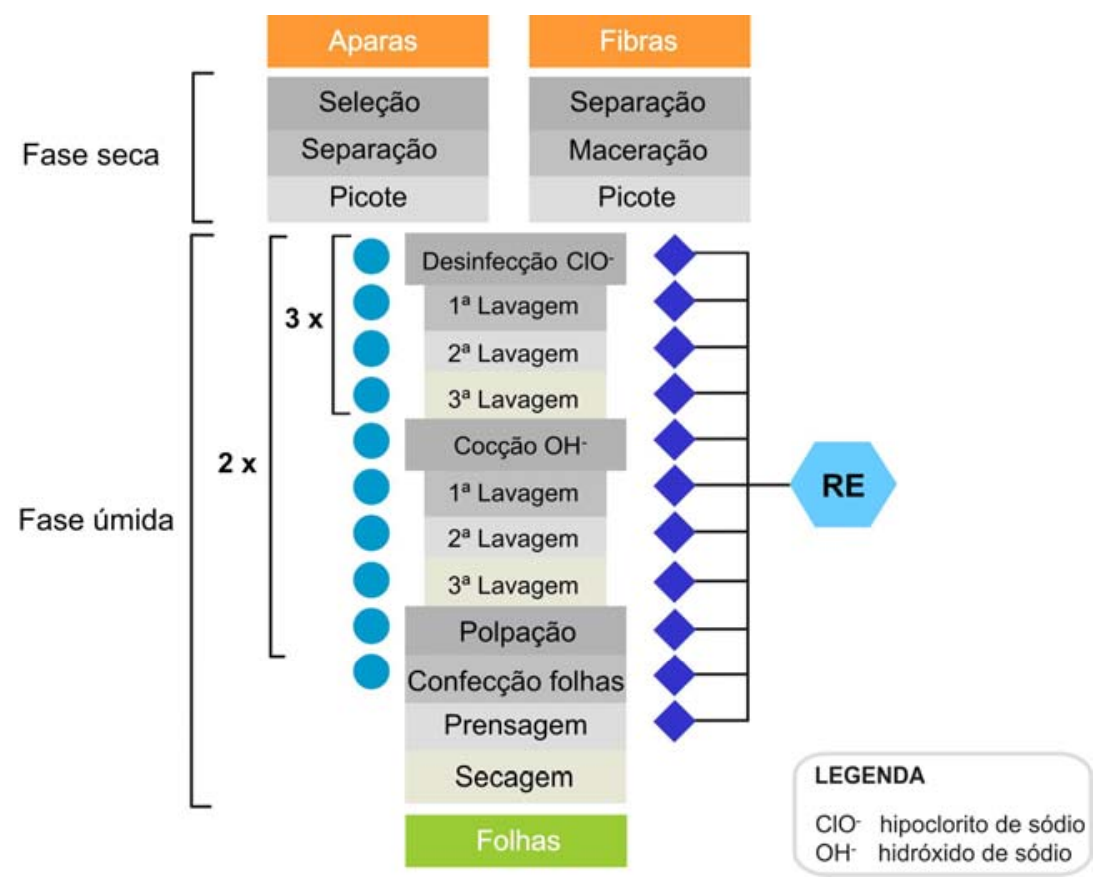

Figura 1: Fluxograma do processo de fabricação de polpa e folhas de papel reciclado artesanal e pastas de bananeira e palha de arroz. Fonte: BARAUNA [18]

\subsection{Caracterização físico-mecânica}

Os corpos de prova foram ensaiados de acordo com normas específicas: gramatura (NBR NM ISO 536-2000), espessura (NBR NM ISO 534-2000) e permeância ao ar (método Bendtsen) (NBR 14255:2002), resistência à tração e alongamento (NBR NM ISO 1924-2:2001), resistência ao esmagamento do anel (NBR 14259:1998), resistência ao arrebentamento (NBR NM ISO 2758:2001). Todos os testes foram realizados a $(23 \pm 1)^{\circ} \mathrm{C}$ e $(50 \pm 2) \%$ de umidade relativa, com no mínimo 5 corpos de prova. Os resultados foram tratados estatisticamente aplicando-se o teste Q de rejeição de resultados [19], registrados graficamente utilizando o software Origin 7.0, apresentando a média e desvio padrão. 


\section{RESULTADOS E DISCUSSÃO}

Para simplificar a análise e discussão, os ensaios foram agrupados em físicos e mecânicos para as amostras de papéis artesanalmente reciclados contendo as pastas de palha de arroz e bananeira nos três percentuais propostos.

\subsection{Ensaios físicos}

Os ensaios físicos, apresentados na Figura 2, compreenderam os testes de gramatura, espessura e permeância ao ar.
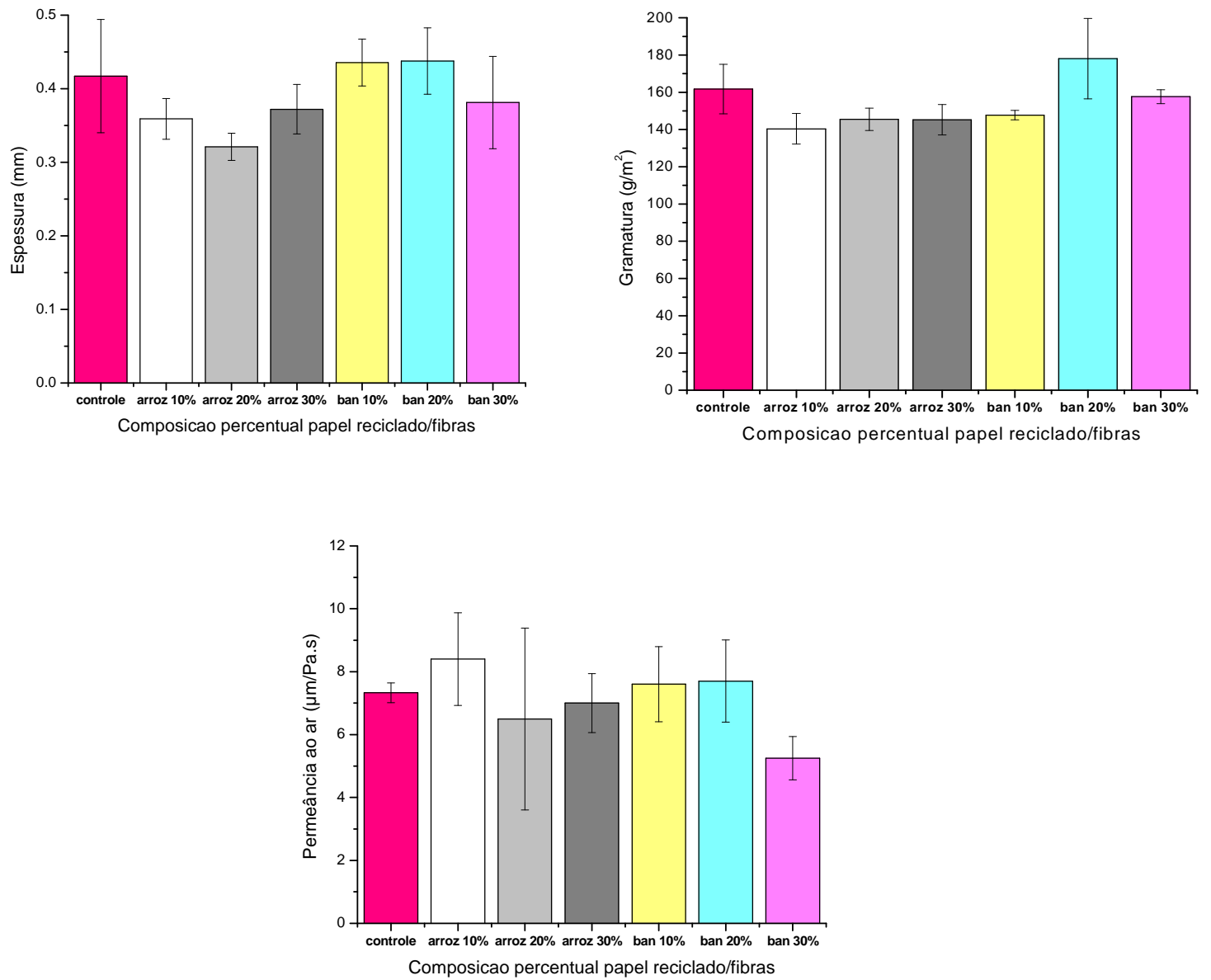

Figura 2: Ensaios de gramatura, espessura e permeância ao ar de amostras de papéis com palha de arroz e pasta de bananeira em percentuais de $0,10,20$ e $30 \%(\mathrm{~m} / \mathrm{m})$.

É possível observar que os papéis desenvolvidos apresentaram gramatura variando entre 140 e 180 $\mathrm{g} / \mathrm{m}^{2}$, sendo que as folhas com 20 e $30 \%(\mathrm{~m} / \mathrm{m})$ de pasta de bananeira e da amostra controle apontaram valores superiores às folhas com pasta de palha de arroz.

Em relação à espessura, os dados obtidos variaram entre 0,33 e 0,44 mm. As amostras de papel com adição de pasta de bananeira também apresentaram espessura similares à amostra controle, em torno de 0,4 $\mathrm{mm}$, superior quando comparadas com pasta da palha do arroz, principalmente com percentuais mais baixos (10 e $20 \% \mathrm{~m} / \mathrm{m}$ ) de pasta. As folhas com $20 \%$ (m/m) de pasta de palha de arroz registraram espessura inferior às demais. Andrade et al. [13] registraram valores de 177 e $221 \mathrm{~g} / \mathrm{m}^{2}$ para papéis artesanais obtidos com 20\% $(\mathrm{m} / \mathrm{m})$ de pasta de bambu ou bagaço de cana, respectivamente sugerindo que o tipo de pasta aplicada exerce influência distinta na gramatura. As fibras vegetais variam muito em diâmetro, comprimento, em virtude de sua origem, bem como das condições edafoclimáticas, que irão interferir na espessura dos papéis e afetar principalmente a opacidade e as propriedades de resistência do papel. 
Os resultados do ensaio de permeância ao ar oscilaram entre 5 e 8,6 $\mu \mathrm{m} / \mathrm{PA}$.s. Embora não seja possível fazer uma correlação entre o aumento percentual ou tipo de pasta com a permeância ao ar, o resultado deste ensaio indicou que as folhas de papel com $30 \%(\mathrm{~m} / \mathrm{m})$ de pasta de bananeira registraram permeância ao ar inferior às demais, sendo mais indicadas para impressão. A variação desta propriedade observada pode ser atribuída ao método artesanal de produção e conseqüentemente à ausência de cargas minerais que ocupam esses poros quando as folhas são obtidas pelo método tradicional [17]. O papel poroso favorece a penetração da tinta e muitas vezes podem ocasionar sérios defeitos de impressão, podendo determinar a escolha do sistema de impressão [르].

Além disso, em relação à arte gráfica, as folhas contendo pasta de bananeira apresentaram características óticas melhores, ou seja, são menos perceptíveis na composição, quando comparadas aquelas com pasta de arroz, alia-se a isso os valores encontrados para a gramatura, o que conforme sugere Andrade [13], torna-as aptas para a produção de embalagens.

\subsection{Ensaios mecânicos}

A Figura 3 ilustra os resultados obtidos para o índice de tração, alongamento, resistência ao esmagamento do anel e resistência ao arrebentamento. Os resultados de índice de tração das folhas oscilaram entre 2,3 e $4,2 \mathrm{~N} . \mathrm{m} / \mathrm{g}$. O desempenho observado para as folhas com $20 \%(\mathrm{~m} / \mathrm{m})$ de pasta de bananeira foi semelhante ao controle, apresentando índice da ordem de 3,3 N.m/g. O índice de tração para a maioria dos papéis é maior na direção longitudinal à fabricação das folhas do que na transversal, pois na primeira as fibras estão alinhadas e exerce uma resistência maior, isto não ocorre no caso de papéis reciclados artesanais, pois as fibras apresentam múltiplas direções. Assim, em todas as amostras as fibras estão dispostas de forma aleatória e, portanto o desempenho apresentado naquelas contendo $20 \%(\mathrm{~m} / \mathrm{m})$ de pasta de bananeira reflete a contribuição percentual dessa fibra.

Os valores de alongamento variaram entre 1,5 e 6,5\%, sendo que todas as composições contendo as pastas vegetais registraram valores inferiores ao controle, mostrando que a origem da pasta vegetal não exerceu influência. Fato semelhante foi descrito por Andrade [13] para papéis obtidos com 20\% (m/m) de pasta de bambu ou bagaço de cana de açúcar.
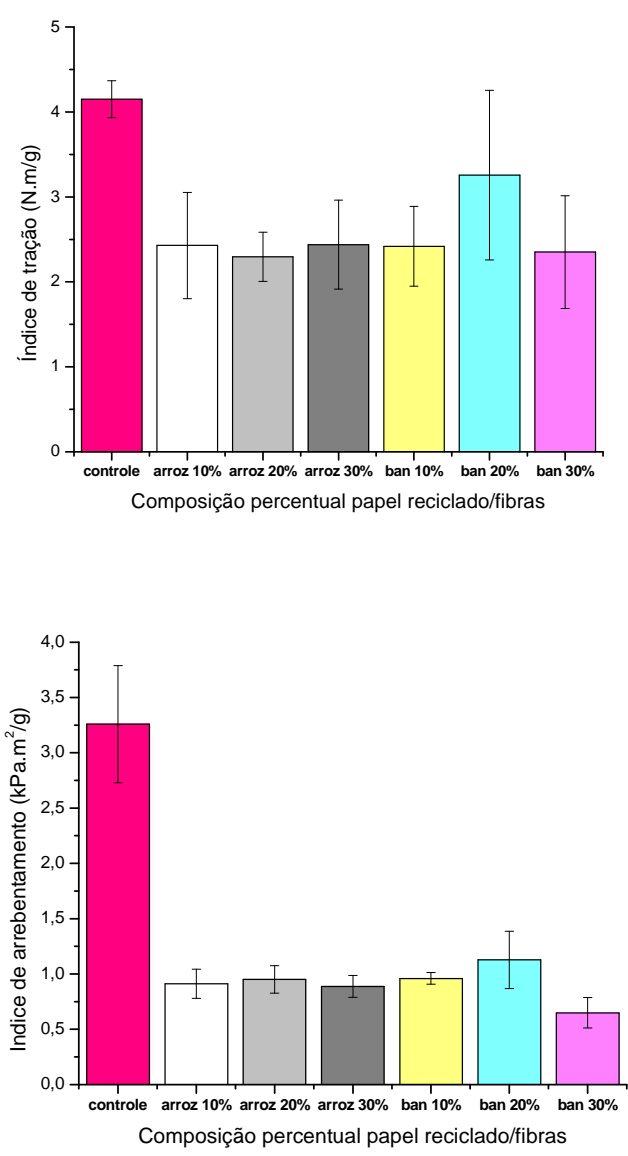
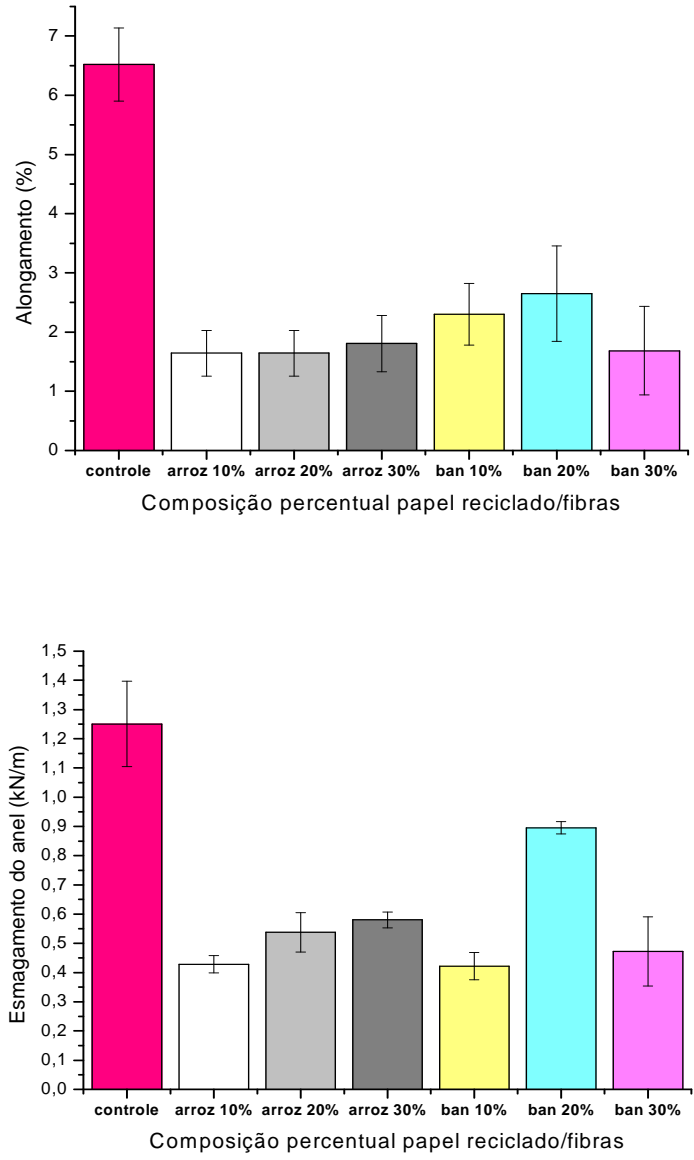
Figura 3: Resultados de índice de tração, alongamento, resistência ao esmagamento do anel e índice de arrebentamento de amostras de papéis com pasta de bananeira e palha de arroz em percentuais de 0, 10, 20 e $30 \%(\mathrm{~m} / \mathrm{m})$.

Os dados registrados para o ensaio de esmagamento do anel oscilaram entre 0,42 e 1,25 kN/m, sendo que o valor máximo foi apresentado pela amostra controle. Assim como no ensaio sob tração, as folhas com $20 \%(\mathrm{~m} / \mathrm{m})$ de pasta de bananeira apresentaram valor na ordem de $0,91 \mathrm{kN} / \mathrm{m}$, superior às demais composições.

Em relação ao índice de arrebentamento, os resultados obtidos variaram de 0,65 a 3,26 kPa.m²/g, sendo que a amostra controle alcançou o valor máximo. Mais uma vez, as folhas com $20 \%$ (m/m) de pasta de bananeira se destacaram em relações às demais.

Embora as propriedades mecânicas dos papéis reciclados com pastas nao-madeireiras tenham apresentados resultados inferiores à amostra controle, as propriedades físicas não foram alteradas de forma significativa. Além disso, o papel reciclado fabricado artesanalmente, normalmente possui uma qualidade estética superior ao do processo industrial, sendo frequentemente utilizado para a confecção de produtos artesanais e também gráficos, como: convites, cartões timbrados, folhetos e edições especiais. As folhas controle e produzidas com pasta de bananeira foram avaliadas sob três sistemas de impressão: serigrafia, offset e jato de tinta por Nascimento et al. [21] sendo que a serigrafia mostrou-se mais adequada para ser usada sobre folhas com pasta de bananeira.

\section{CONCLUSÕES}

Analisados os ensaios físicos e mecânicos, constatou-se que os resultados mais expressivos foram registrados para as folhas que continham $20 \%(\mathrm{~m} / \mathrm{m})$ de pasta de bananeira. As amostras de papel com adição de pasta de bananeira também apresentaram espessura similares à amostra controle e superior quando comparadas com pasta da palha do arroz, principalmente com percentuais mais baixos de pasta. As folhas de papel com 30\% (m/m) de pasta de bananeira registraram permeância ao ar inferior às demais, sendo mais indicadas para impressão. Além disso, as amostras de papéis com pasta de bananeira apresentaram gramatura superior às folhas com pasta de arroz, bem como maior espessura e menor interferência visual em relação aos papéis com pasta de palha de arroz, o que para uma embalagem, sua forma e possíveis grafismos aplicados são essenciais.

Em relação aos ensaios mecânicos, a amostra controle mostrou desempenho superior em relação às demais amostras. Por outro lado, dentre as folhas com pasta vegetal, aquelas contendo $20 \%$ (m/m) de pasta de bananeira destacaram-se, principalmente nos ensaios de esmagamento do anel e arrebentamento.

\section{AGRADECIMENTOS}

Os autores agradecem auxílio financeiro fornecido através do Fundo de Apoio à Pesquisa (FAP/UNIVILLE) e ao Instituto de Pesquisas Tecnológicas (IPT).

\section{REFERÊNCIAS}

[1] SILVA, R.P., OLIVEIRA, R.C., “Efeitos da ação do refino e da reciclagem nas propriedades de papéis de pinus e eucalipto”, Revista Árvore, v. 24, n. 2, pp. 349-360, 2000.

[2] D’ALMEIDA, M.L.O., Bate-Papo on-line: reciclagem de papel: virtudes e mitos. Disponível em http://www.ipt.br/atividades/servicos/chat/?ARQ=19. Acessado em 2007.

[3] AMARAL, M., NASCIMENTO, E.Z., STAFFORD, F., BARAUNA, D., ANSELMO, J.S., PEZZIN, A.P.T, SILVA, D.A.K., "Aperfeiçoamento tecnológico para uma oficina de papel reciclado artesanal: um estudo de caso”, Caderno de Iniciação a Pesquisa, v. 10, pp. 175-178, 2008.

[4] ANSElmo, J.S., BARAUNA, D., NASCiMENTO, E.Z., ROSA E SILVA, L.N., POZZA, A.M.O., SILVA, D.A.K., “O design na produção artesanal: uma aplicação na extensão universitária”, Congresso Brasileiro de Extensão Universitária, CBEU, 2009.

[5] VILLANUEVA, A., WENZEL, H., "Paper waste - recycling, incineration or landfilling? A review of existing life cycle assessments”, Waste Management, v. 27, pp. 29-46, 2007. 
[6] MATHUR, V.K., “Composite materials from local resources”, Construction and Building Materials, v. 20, pp. 470-477, 2006

[7] DALlAGNOL, E.C., BARAUNA, D., ANSELMO, J.S., PEZZIN, A.P.T., “Aplicação de corantes naturais extraídos de vegetais no tingimento da polpa de papel com variações de mordentes”, In: Congresso Brasileiro de Ciência e Engenharia de Materiais - CBCIMAT, Porto de Galinhas, Anais do $18^{\circ}$ CBECIMAT, pp. 5208-5217, 2008.

[8] VIEIRA, L.M., Síntese anual da agricultura de Santa Catarina 2007-2008, Disponível em http://cepa.epagri.sc.gov.br/publicacoes/sintese_2008/banana.pdf. Acessado em 21/01/2010.

[9] SOFFNER, M.L.A.P., Produção de polpa celulósica a partir de engaço de bananeira, Dissertação de M.Sc., Escola Superior de Agricultura "Luiz Queiroz"/Ciência e Tecnologia de Madeira/USP, Piracicaba, SP, 2001.

[10] RAJARATHNAM, S., SHASHIREKHA, M.N., ZAKIA BANO., "Biopotentialities of the basidiomacromycetes”, Advances in Applied Microbiology, v. 37, pp. 234-361, 1992.

[11] MARIOT, C.H.P., SILVA, P.R.F., MENEZES, V.G., TEICHMANN, L.L., "Resposta de duas cultivares de arroz irrigado à densidade de semeadura e à adubação nitrogenada”, Pesquisa Agropecuária Brasileira, v. 38, n. 2, pp. 233-241, 2003.

[12] BONATTI, M., Estudo do potencial nutricional de corpos frutíferos de Pleurotus ostreatus cultivados em palha de arroz e em palha de bananeira, Dissertação de M.Sc., UFSC, Florianópolis, SC, Brasil, 2001.

[13] ANDRADE, A.M., DUARTE, A.P.C., BELGACEM, M.N., MUNARO, E.R., "Produção de papéis artesanais das misturas de aparas com fibras virgens de bambu (dendrocalamus giganteus) e de bagaço de cana-de-açúcar (saccharum officinarum)”, Floresta e Ambiente, v. 8, n. 1, pp.143-152, 2001.

[14] ABRAnTES, S., AMARAL, M.E., COSTA, A.P., DUARTE, A.P., "Cynara cardunculus L. alkaline pulps: alternatives fibres for paper and paperboard production”, Bioresource Technology, v. 98, pp. 2873-2878, 2007.

[15] BASTIANELLO, S.F., KRIECK, T., PEZZIN, A.P.T., SILVA, D.A.K., "Desenvolvimento de embalagens a partir de papel reciclado reforçado com fibras de bananeira: uma proposta ambientalmente amigável”, Revista Expressão, v. 1, n. 1, pp. 64-70, 2005.

[16] BASTIANELLO, S.F., Desenvolvimento de embalagem a partir de papel reciclado reforçado com fibras naturais: uma proposta ambientalmente amigável, Dissertação de M.Sc, MSMA/UNIVILLE, Joinville, SC, Brasil, 2005.

[17] ASUNCIÓN, J., O papel: técnicas para confecção de papéis artesanais, 2 ed., Lisboa, Estampa, 2002.

[18] BARAUNA, D. Sistema de gestão ambiental (SGA): uma aplicação na produção de papel reciclado artesanal com adição de diferentes frações mássicas de fibras de bananeira. Dissertação de M.Sc., MSMA/UNIVILLE, Joinville, SC, 2009.

[19] SILVA, D.A.K., GIOVANELA, L.E.M., BONATTI, M., APATI, G.P., "Efeito da degradação de extratos de Allium sativum I (Liliiflorae - Liliaceae) no crescimento de microrganismos patogênicos”, Caderno de Iniciação à Pesquisa, v. 4, pp. 25-31, 2002.

[20] BAER, L., Produção gráfica, São Paulo: Senac, 1999.

[21] NASCIMENTO, E.Z, ANSELMO, J.S., BARAUNA, D., PEZZIN, A.P.T., SILVA, D.A.K., “Aplicação de sistemas de impressão em papel reciclado artesanal utilizando diferentes frações mássicas de fibra de bananeira”, In: $8^{\circ}$ Congresso Brasileiro de Pesquisa e Desenvolvimento em Design (P \& D Design), São Paulo, Anais do P \& D Design, pp. 163-172, 2008. 